\title{
COMPLICATIONS OF OPEN SURGICAL PROCEDURES IN PATIENTS WITH PANCREATIC CYSTS
}

\author{
Aleksandr Gerasimov ${ }^{凶}$, Valeriy Nikolskiy (D), \\ Aleksandr Mitroshin $(\mathbb{D}$, Sergey Frolov (D), \\ Ekaterina Titova
}

Penza State University, Medical Institute, Penza, Russia

gerasimov-av30@yandex.ru

ABSTRACT - The incidence of pancreatic cysts is constantly growing due to an increasing number of patients with a history of pancreatitis. Furthermore, complications after surgical interventions for pancreatic cysts occur in $30-40 \%$ of patients.

OвJестіve: to analyze the complications in patients with pancreatic cysts after open surgery.

We observed 68 patients who underwent open surgical interventions: cystogastrostomy and cystojejunostomy. All patients with pancreatic cysts were divided into 2 groups depending on the type of procedure. In 27 patients $(29 \%)$ of the first group cystogastrostomy and in 41 patients (81\%) of the second group cystojejunostomy was performed. In $1^{\text {st }}$ group complications were diagnosed in 8 cases (29.6\%): postoperative pancreatitis $(5-18.5 \%)$, cyst recurrence $(3-11.1 \%)$. In the second group complications occurred in 7 patients (17.1\%): postoperative pancreatitis in 4 cases $(9.8 \%)$, recurrent cysts in 3 cases $(7.3 \%)$.

Thus, cystojejunostomy is less associated with complications than cystogastrostomy.

KEYWORDS - pancreatic cyst, chronic pancreatitis, cystogastrostomy, cystojejunostomy.

\section{RELEVANCE}

Acute pancreatitis is considered the single most frequent gastrointestinal cause of hospital admissions in the United States. Chronic pancreatitis being lower in incidence noticeably worsens patients' quality of life. In recent decades researchers worldwide have witnessed an increase in patients with a history of pancreatitis, and as a result, the presence of pancreatic cysts in this group of patients $[1,2,3]$. According to scientific literature the process of formation of pancreatic cysts is often accompanied by the appearance of severe complications: mechanical jaundice, perforation, suppuration of cysts, peritonitis, bleeding, etc. $[4,5,6]$. After open surgical interventions complications occur in $30-40 \%$ of cases. Those complications are quite variable: from the most severe, such as bleeding, peri- tonitis, abscesses, to the milder, that could be stopped conservatively or with the help of minimally invasive procedures - postoperative pancreatitis, recurrent pancreatic cysts. These complications are often associated with high pressure on the anastomosis caused by increased pancreatic secretion, as well as technical intraoperative difficulties $[7,8]$.

\section{Objective:}

to evaluate complications in patients with pancreatic cysts after open surgical procedures.

\section{MATERIAL AND METHODS}

The work has been carried out in surgical departments of Penza Regional Clinical Hospital named after N. N. Burdenko. The study involved 68 patients who underwent open surgical interventions: cystogastrostomy and cystojejunostomy. There were 12 women (20.7\%) and 56 men (79.3\%). The age of patients ranged from 22 to 74 years. The average age was $57 \pm 9.8$ years. Pancreatic cysts were identified: in the tail of the gland in 6 patients (10.3\%), in the body of the pancreas in 8 patients (13.7\%), in the head of the pancreas in 54 patients $(75.7 \%)$.

At the first stage 59 patients (84.4\%) underwent external drainage of pancreatic cysts under ultrasound control. The remaining 6 patients $(15.5 \%)$ did not undergo this procedure.

Indications for external drainage of cysts were: an increase in the size of the cyst more than $50 \mathrm{~mm}$, a loose, unformed cyst wall, signs of infection of cysts, as well as the severity of the patient's condition.

For diagnostic purposes in the patients with pancreatic cysts the following general clinical and laboratory tests were performed: blood type and Rh factor, common blood test, biochemical blood test, general urine test, urine diastasis, coagulogram; instrumental examinations: electrocardiography, ultrasound examination of the abdominal cavity and retroperitoneal space, fibrogastroduodenoscopy, computed tomography of the abdominal cavity and retroperitoneal space, X-ray examination of the chest and abdominal cavity (fistulography after drainage of pancreatic cysts was performed to identify the connection with the pancreatic duct), magnetic resonance imaging of the abdominal cavity and retroperitoneal space. 
All patients with pancreatic cysts were divided into 2 groups, depending on the type of surgery performed. Group 1 included 27 patients who underwent cystogastrostomy (29\%), group 2 included 41 patients where cystojejunostomy was done (81\%).

Indications for cystogastrostomy and cystojejunostomy were: the size of the pancreatic cyst more than $60 \mathrm{~mm}$, the formation of the pancreatic cyst wall, as well as the presence of a proven instrumental connection between the cyst and the pancreatic duct.

Cystrogastrostomy was performed in patients with a pronounced adhesive process in the abdominal cavity, with the fusion of the cyst wall with the posterior wall of the stomach. Cystojejunostomy was performed in all remaining cases.

\section{RESULTS AND DISCUSSION}

In group 1 after surgery, complications were diagnosed in 8 cases (29.6\%): cyst recurrence in 3 patients, postoperative pancreatitis in 5 patients.

In 5 cases (18.5\%), the development of postoperative pancreatitis was revealed with clinical manifestations on the $4^{\text {th }}-5^{\text {th }}$ day after surgery. After conservative therapy, patients were discharged in 15-16 days in a satisfactory condition. The following scheme of conservative treatment has been used: non-narcotic analgetics (ketorol $1.0 \mathrm{v} / \mathrm{m}$ ), NSAIDs (ibuprofen $3.0 \mathrm{v} / \mathrm{m}$ ), antispasmodics (no-shpa $2 \%-2.0$, platyphylline $0.2 \%-1.0 \mathrm{v} / \mathrm{v}$ ), infusion therapy in the volume of $20-30 \mathrm{ml} / \mathrm{kg}$ of weight was used; drugs that reduce pancreatic secretion (atropine $0.1 \%-1.0 \mathrm{i} / \mathrm{v}$ ), as well as inhibitors of protease activity (kontrikal 20,000 units 2 p.i/v or gordox 100.000 units).

In the long-term postoperative period in 3 cases (11.1\%) the cyst recurrence was detected (after 4 months during a routine ultrasound examination). No clinical manifestations of pancreatitis were noticed. The level of amylase activity in all cases was within the normal range. The size of the liquid collector in the first case was $18 \mathrm{~mm}$, in the second $-29 \mathrm{~mm}$, in the third $-38 \mathrm{~mm}$. Dynamic follow-up at the surgeon's place of residence is recommended.

Complications occurred in 7 patients (17.1\%) in the $2^{\text {nd }}$ group. Postoperative pancreatitis was observed in 4 patients (9.8\%). In the course of treatment (conservative therapy) acute pancreatitis was stopped on the $12^{\text {th }}-16^{\text {th }}$ day from the moment of hospitalization. Recurrence of a pancreatic cyst was detected during a routine ultrasound examination in 3 patients $(7.3 \%)$ in the long-term postoperative period (from 4 to 6 months after surgery). Infection of the cyst cavity occurred in one case. In the postoperative period this patient suffered from acute pancreatitis. During the next hospital readmission, the liquid formation in the projection of the tail of the pancreas with dimensions of $75 \times 62 \times 67 \mathrm{~mm}$ was revealed. The cyst cavity was drained under ultrasound control, and cloudy contents with a fetid smell were obtained. After that procedure no clinic of acute pancreatitis were revealed.

After the surgical treatment in the second group of patients the length of hospital stay was maximum 16 days, minimum $-7(12 \pm 1.4$ days). In the first group the period of hospital stay was $15 \pm 1.35$ (from 12 to 19 days).

Thus, the total number of complications in 1 group was $29.6 \%$, where postoperative pancreatitis was detected in $18.5 \%$, and recurrent pancreatic cysts - in $11.1 \%$. In 2 group patients, complications were observed in $17.1 \%$ : postoperative pancreatitis $(9.8 \%)$ and recurrent pancreatic cysts $(7.3 \%)$. The duration of treatment in patients after cystograstrostomy was 15 days, after cystojejunostomy -12 days. There were no fatal outcomes after surgical interventions in patients with pancreatic cysts.

\section{CONCLUSION}

We consider it more appropriate to perform Roux-en-Y cystojejunostomy on a disconnected loop, since the postoperative period with such a surgical intervention is accompanied by fewer complications (by 1.7 times $-p=0.017$ ) and a shorter length of hospital stay. The median postoperative LOS after cystogastrostomy is 1.25 times more than after cystojejunostomy.

\section{REFERENCES}

1. Yadav D., Lowenfels A. B. The Epidemiology of Pancreatitis and Pancreatic Cancer. Gastroenterology. 2013, 144(6): 1252-1261. https://doi.org/10.1053/j. gastro.2013.01.068

2. KozHeVNiKov V.V., Gerasimov A.N., GeraSIMOV N.A., Morozov V.S. The result of treatment of patients with bleeding from postnecrotic cysts of the pancreas // In the collection: National projects: challenges and solutions. Materials of the $55^{\text {th }}$ interregional scientific and practical medical conference. Ministry of Health of the Ulyanovsk Region; GBU SPb Research Institute of Ambulance named after N.I. I.I. Janelidze. Ulyanovsk, 2020. P. 487-488.

3. Beyer G., Goni E., Köpke M., G D'Haese J., Werner J., Schirra J., Mayerle J. Management Algorithm for Cystic Pancreatic Lesions / / Visc Med. 2018. Jul;34(3):197-201. doi: 10.1159/000489233.

4. Sklyarenko R.T., Dovgalyuk A.Z., Omarov M.A., Spiridonova V.S., Shabanova O.A. Consequences of surgical treatment of diseases of the pancreas (chronic pancreatitis, cysts and fistulas of the pancreas) // In the book: Clinical and expert characteristics of persistent dysfunctions in surgical diseases and the possibility of rehabilitation. St. Petersburg. 2017. P. 355-375. 
5. Cherdantsev D.V. Diagnostics of postnecrotic pancreatic cysts (literature review) / Cherdantsev D.V., Pervova O.V., Noskov I.G., Fokin D.V., Kazadaeva A.A., Kazadaeva I.A. // Messenger of Surgery I.I. Grekov. - 2020. Vol. 179. N. 2. P. 68-72.

6. Koshel A.P., Drozdov E.S., Dibina T.V., KLOKov S.S., Mironova E.B., Rakina Yu.Yu. Combined method for differential diagnosis of cystic neoplasms of the pancreas // Siberian Journal of Oncology. 2018. - Vol. 17. - N.6. - P. 27-34.
7. Chudoba A, Degowska M, Oracz G. Multilocular Cyst of the Pancreas // Indian J Pediatr. 2020. N. 87(11). P. 965.

8. Cao C.X., Sharib J.M., Blanco A.M., GoldBerg D., Bracci P., Mukhtar R.A., EsSerMAN L.J., KIRKWOOD K.S. Abdominal Imaging of Pancreatic Cysts and Cyst-Associated Pancreatic Cancer in BRCA1/2 Mutation Carriers: A Retrospective Cross-Sectional Study / / J Am Coll Surg. 2020 Jan;230(1):53-63.e1. doi: 10.1016/j.jamcollsurg.2019.09.019. 